\title{
Análisis jurisprudencial binacional: Poder tributario, vejez y derechos fundamentales
}

Binational jurisprudential analysis: Tributary power, old age and fundamental rights

\author{
Marco Antonio Pontigo Donoso (iD
}

Universidad de Buenos Aires, Argentina

\begin{abstract}
RESUMEN Este artículo pretende efectuar un análisis descriptivo y comparativo de dos sentencias dictadas en el primer semestre del año 2019 por los Tribunales Superiores de Justicia de Argentina y Chile, sobre el poder impositivo, vejez y protección de las garantías constitucionales de las personas pensionadas, las que tienen varios denominadores en común: a) las recurrentes son mujeres; b) ambas son contribuyentes pasivas; c) ambas están pensionadas o jubiladas; $y \mathrm{~d}$ ) una y otra dirigieron sus acciones en contra de órganos de la Administración del Estado del orden tributario.
\end{abstract}

PALABRAS CLAVE Impuestos, vejez, pensiones y garantías fundamentales.

\begin{abstract}
The work intends to carry out a descriptive and comparative analysis of two sentences issued in the first semester of 2019, by the Superior Courts of Justice of Argentina and Chile, which deal with the power of taxation, old age and protection of the constitutional guarantees of persons pensioners, which have several denominators in common: a) the recurrent are women; b) both are passive contributors; c) both are pensioned or retired; and d) both directed their actions against the organs of the State Administration, of the tax order.
\end{abstract}

KEYWORDS Taxes, old age, pensions and fundamental guarantees.

\section{Introducción}

Este artículo pretende efectuar un análisis descriptivo y comparativo de dos recientes sentencias dictadas por los Tribunales Superiores de Justicia de Argentina y Chile, sobre el tema impositivo, las que tienen varios denominadores en común: las recurrentes son mujeres; ambas son contribuyentes pasivas; ambas están pensionadas o jubiladas; y ambas dirigieron sus acciones en contra de órganos de la Administración del Estado, del orden tributario. 
Estas sentencias se pronunciaron luego del conocimiento y sustanciación de ciertas acciones cautelares que estas contribuyentes ejercieron en contra de las agencias de control tributario, transformando la acción jurisdiccional del más alto nivel en un dique limitante y contenedor del nuevo y fortalecido poder tributario imperante en ambas naciones, que se expresa, entre otras formas, en la denominada y cada vez más palpable presión tributaria, destinada a incrementar la recaudación fiscal.

\section{Antecedentes de las causas}

Tanto en la Argentina como en Chile, en los meses de marzo y mayo de 2019, respectivamente, se dictaron y conocieron dos significativas sentencias: la primera de ellas fue pronunciada por la Corte Suprema de Justicia de la Nación Argentina (CSJN), precisamente el 26 de marzo de este año, relativa al impuesto a las ganancias sobre el monto de la jubilación o pensión; por su parte, la segunda fue emanada por la Corte Suprema de Justicia de la República de Chile (CS) el día 2 de mayo, referida a una exención o beneficio tributario del impuesto territorial. Coincidieron en los siguientes aspectos: ambas fueron favorables y prodigaron amparo a derechos fundamentales de dos mujeres que se encontraban en el estatus jurídico de pensionadas, aunque recurrieron por diferentes vías en contra de sus respectivas autoridades administrativas tributarias, por cuanto, a su juicio, los entes públicos habían actuado con desmedido celo recaudatorio, o directamente en forma arbitraria e ilegal, pretendiendo cobrar diversas clases de impuestos, afectando con ello sus derechos fundamentales y provocando una especial sensación de vulnerabilidad en las recurrentes, en consideración a su difícil situación derivada de su calidad de extrabajadoras, con un nivel de ingresos económicos distinto al de su época de productividad plena.

En este caso argentino (Sentencia de la Corte Suprema de Justicia de la Nación Argentina, roles FPA 7789/2015/CS1-CA1 y FPA 7789/2015/1/RH1, de 26 de marzo de 2019), ${ }^{1}$ la CSJN conoció una causa que provenía de la Cámara Federal de Paraná, que había confirmado la sentencia de primera instancia, que hizo lugar a la demanda, y en consecuencia, declaró la inconstitucionalidad del artículo 79 letra c) de la Ley de Impuestos a las Ganancias (Ley de Argentina 20.628 de 1973) y sus modificaciones, y además ordenó el reintegro de los tributos pagados vía retención a la actora, una exdiputada y docente de la Provincia de Entre Ríos, pensionada, a la cual en los meses de marzo a mayo del año 2015, se le hicieron descuentos que oscilaron entre el 29 y $31 \%$ de su beneficio jubilatorio.

El reclamado o demandado era la Administración Federal de Ingresos Públicos (AFIP), que es el organismo que tiene a su cargo la ejecución de la política tributaria, aduanera y de recaudación de los recursos de la seguridad social de la Nación Argentina (según Decreto de Argentina 618 de 1997).

Del arbitrio en estudio, se colige que la cuestión federal planteada por la AFIP, en la

1. Fallo disponible en http://bit.ly/35SC9In. 
queja, consiste en determinar la validez constitucional de la Ley 20.628, que grava con el impuesto a las ganancias a las rentas provenientes de las jubilaciones, pensiones, retiros o subsidios de cualquier especie en cuanto tengan su origen en el trabajo personal.

La gran virtud de fallo de la CSJN en comento es que, a través de una densa y fluida redacción, da cuenta de una serie de razonamientos y argumentos que le permiten construir el voto mayoritario que acoge la acción, dentro de las que destacan las siguientes reflexiones:

- Se enarbola el Principio Constitucional de Integralidad del Haber Previsional, reconocido por otras sentencias de esa Corte y por fallos de tribunales internacionales, ${ }^{2}$ entendiendo que la jubilación no es una ganancia, sino que un debito que tiene la sociedad con el jubilado que le permite gozar de un beneficio cuando la capacidad laborativa disminuye o desaparece. Debido a ello, señala el fallo, al ser el haber previsional una suma de dinero que se ajusta al parámetro de la integralidad, «esta no puede ser pasible de ningún tipo de imposición tributaria».

- La sentencia reconoce la importancia del Principio Republicano de División de Poderes, respetando el derecho constitucional del Poder Legislativo, contenido en los artículo 4, 17 y 75 de la Constitución de la Nación Argentina, de poder elegir los objetos imponibles, determinar las finalidades de la percepción y disponer los modos de valuación de los bienes o cosas sometidos al gravamen. Pero con la misma fuerza, la Corte reconoce su esfera de competencia, la que dice relación con el irrenunciable y debido control judicial de lo que denomina «imperativo constitucional», el que enmarca la labor del legislador cuando crea tributos, ya que estos no pueden desentenderse del resto del sistema jurídico, operar aisladamente y afectar los derechos y garantías de las personas. Y en este sentido, la CSJN citando a Rafael Bielsa, nos recuerda que ante la lesión de una garantía constitucional, el control jurisdiccional surge y se coloca sobre la propia discrecionalidad política (Sentencia de la Corte Suprema de Justicia de la Nación Argentina, roles FPA 7789/2015/CS1-CA1 y FPA 7789/2015/1/RH1, de 26 de marzo de 2019: considerando 16).

- Reconoce, desarrolla y aplica, como límites superiores a la Potestad Estatal Tributaria los Principios Constitucionales de Igualdad y de Razonabilidad, entendiendo el primero como una garantía de que la ley concederá un trato igualitario a quienes se hallan en una razonable igualdad de circunstancias, lo que no impide que el legislador contemple de manera distinta situaciones que considere diferente; y el segundo lo comprende como un mandato de prudencia y sabiduría, en virtud del cual el Poder Legislativo, al ejercer su amplia y libre potestad para

2. Por ejemplo, Sentencia de la Corte Interamericana de Derechos Humanos caratulada «Cinco Pensionistas vs Perú», de 28 de febrero de 2003. 
ordenar, agrupar, distinguir y clasificar objetos de la legislación, lo hará con la condición de que todos esos objetos sean colocados en una clase o categoría y de que recibirán, por tanto, el mismo tratamiento.

- La CSJN nos señala y representa el reconocimiento a los «derechos de la ancianidad» receptados por la Constitución de la Nación Argentina y examinados por la jurisprudencia de ese tribunal. Al efecto, invoca como fuente la reforma del año 1949 que otorgó jerarquía constitucional a los derechos sociales o de seguridad social, los que apuntan a dignificar la vida de los trabajadores para protegerlos en la incapacidad y la vejez; cita la reforma del año 1994, que impulso el desarrollo del principio de igualdad sustancial para el logro de una tutela efectiva de colectivos de personas en situación de vulnerabilidad, permitiéndose la discriminación positiva; y además se basó en los instrumentos internacionales promovidos por la Asamblea General de las Naciones Unidas de los años 1982 y 2002, relativos al envejecimiento, así como en la Convención Interamericana sobre la Protección de los Derechos Humanos de las Personas Mayores, donde se contempla el derecho que tiene toda persona mayor a la seguridad social que la proteja para llevar una vida digna.

- Ahondando en el tema, la CSJN nos indica que el envejecimiento y la discapacidad son los motivos más comunes por los cuales se accede a una jubilación, y son a la vez las causas predisponentes o determinantes de la vulnerabilidad, circunstancia que normalmente obliga a los concernidos a contar con mayores recursos para no ver comprometida seriamente su existencia y/o calidad de vida y el consecuente ejercicio de sus derechos fundamentales.

- La Corte, además, deja en evidencia que la sola capacidad contributiva como parámetro para el establecimiento de tributo de los jubilados o pensionados resulta insuficiente si no se pondera la vulnerabilidad del colectivo concernido. Por lo tanto, a su juicio, la falta de consideración de esta circunstancia como pauta de diferenciación tributaria supone igualar a los vulnerables con quienes no lo son.

- Finalmente, en esta síntesis destacamos que, dentro de la jurisprudencia de la CSJN en materia de seguridad social, esta ha manifestado su especial sensibilidad a las cuestiones que atañen al resguardo de los créditos de la clase pasiva, a quien identifica como un grupo vulnerable, históricamente postergado, procurando con sus decisiones hacer efectiva la protección que la Constitución de la Nación Argentina garantiza a la ancianidad, a la luz de su artículo 75, inciso vigésimo tercero.

- No obstante la validez de lo resumido, se debe dejar constancia de la existencia del voto disidente del Presidente de la Corte Suprema, el que latamente se hace cargo y desvirtúa cada uno de los argumentos del voto de mayoría, de un modo ejemplar, y que por su intensidad pueden provocar convicción en tal sentido. 
En el caso chileno (Sentencia de la Corte Suprema de la República de Chile rol 2765-2019, de 2 de mayo de 2019) y a modo de sinopsis introductoria de la causa, debemos indicar que la actora se trata de una profesora, pensionada, propietaria de varias unidades sujetas a un tributo real, determinado por la Ley 17.235 de 1969, llamado impuesto territorial, que grava específicamente el inmueble que la recurrente habita como morada principal; la cual, a su vez, estaba amparada con una rebaja significativa de las contribuciones (o impuesto territorial) desde hace algunos años, según lo señalado en Ley 20.732 de 2014, que estableció, en marzo de 2014, la rebaja el impuesto territorial correspondiente a propiedades de adultos mayores vulnerables económicamente.

La recurrente gozó del beneficio con normalidad hasta el inicio del segundo semestre del año 2018, época en que el Servicio de Impuestos Internos (SII), que es el ente administrativo encargado de la aplicación y fiscalización de todos los impuestos internos actualmente establecidos o que se establecieren, fiscales o de otro carácter en que tenga interés el Fisco y cuyo control no esté especialmente encomendado por la ley a una autoridad diferente (de acuerdo al artículo 1 del Decreto Ministerio de Hacienda número 7 de 1980).

El SII modificó unilateralmente el monto de las contribuciones, desconociendo el beneficio de rebaja, aduciendo como fundamento que la contribuyente había perdido la exención parcial debido a que el conjunto de propiedades de las cuales era titular superó el monto máximo de avaluó que permitía invocar tal merced fiscal.

La controversia fue conocida y resuelta en virtud del ejercicio de la acción cautelar de derechos fundamentales conocido como Recurso de protección. En este caso y bajo esas normas procesales, la Corte Suprema actúa como segunda instancia y, en razón de esa competencia transferida, confirma lo establecido en la Sentencia de la Corte de Apelaciones de Santiago, rol 77.252-2018, de 2019, que había acogido la acción cautelar a favor de la profesora pensionada, reproduciendo gran parte del texto de primera instancia, pero eliminando algunos considerandos, los que reemplaza por aquellos que pasamos a resumir.

Podemos indicar que los argumentos y razonamientos del Tribunal Superior fueron los siguientes:

1. La Corte solo centró el debate en la correcta inteligencia del precepto contenido en el artículo 1 de la Ley 20.732, indicando que, mientras la actora alega que cumpliría con el requisito establecido en el numeral 6 de dicha disposición y por tanto es beneficiaria de la rebaja correspondiente al impuesto territorial, la recurrida (el SII) sostiene que cualquier contribuyente que desee acogerse a la rebaja tributaria en comento debe cumplir con todos y cada uno de los requisitos establecidos por la norma, de manera que, si falta cualquiera de ellos, la solicitud debe ser desestimada sin más trámite.

2. Señala la Corte que, si bien el artículo 1 inciso primero de la Ley 20.732 señala que los requisitos allí enunciados deben cumplirse de manera copulativa, esta última expresión no debe ser interpretada desde una perspectiva formalista y literal, toda vez que la interpretación del derecho y de la ley, en particular, constituye una actividad compleja en la que confluyen una serie de elementos, métodos y criterios hermenéuticos que, en 
su conjunto, permiten al intérprete - en este caso, al juzgador- determinar el correcto sentido y alcance de la formulación normativa. ${ }^{3}$

En el mismo sentido la CS, invocando al destacado jurista genovés Riccardo Guastini, nos indica que, en otros términos, el juez no puede limitarse a la interpretación textual. La aplicación del derecho requiere conjuntamente: i) la interpretación de la fuente; y ii) la calificación del supuesto de hecho; la cual presupone a su vez, iii) la subsunción de los hechos en la causa.

Así las cosas, puede afirmarse, a juicio del máximo tribunal, que la interpretación judicial es una actividad que no puede ser reducida a la mera elucidación del sentido gramatical de una palabra contenida en un texto legal, considerada ésta de manera aislada, sino que han de seguirse otras pautas, cánones o criterios que, en su conjunto, deben guiar al intérprete en la búsqueda del genuino sentido y alcance de la disposición. El resultado de la interpretación, así concebido, es la «norma», cuestión que supone diferenciar entre la formulación normativa (el texto) y la norma propiamente tal (el producto de la interpretación).

3. En este afán argumentativo, el tribunal recurre a la historia fidedigna del establecimiento de la ley, donde queda claro que la intención del legislador y la ratio legis que impulsa a la normativa que estableció la rebaja el impuesto territorial (Ley 20.732) no es otra que beneficiar a los adultos mayores en situación de vulnerabilidad económica, precisamente en aquella etapa vital en que los recursos suelen ser escasos y las necesidades múltiples. Es del caso añadir que la medida en comento forma parte de una política pública más amplia, que busca beneficiar a los adultos mayores como un reconocimiento al aporte que realizan en la sociedad.

4. Así, la Corte se convence en esa dirección, y señala que para gozar de la rebaja del impuesto territorial contemplada en el artículo 1 de la Ley 20.732, no es necesario que el contribuyente cumpla simultáneamente con los requisitos contenidos en los numerales $5 .^{\circ}$ y $6 .^{\circ}$ de la señalada disposición, pues es suficiente con que cumpla cualquiera de ellos, alternativamente.

5. Que, por todo lo razonado, la Corte concluyó que la recurrida ha actuado al margen de la ley al no aplicar a la actora la rebaja tributaria contemplada en el artículo 1 de la Ley 20.732, respecto de las cuotas 3 y 4 del año 2018, y las cuotas 1 y 2 del año 2019, todas relativas al pago del impuesto territorial; y cobrar, en cambio, un monto notoriamente superior al que legalmente correspondía si se hubiera aplicado la mencionada rebaja. De ese modo se ha vulnerado la garantía de igualdad ante la ley y el derecho de propiedad, consagrados en el artículo 19 numales $2 .^{\circ}$ y $24 .{ }^{\circ}$ de la Constitución Política, ordenando que la recurrida otorgue el beneficio tributario de la rebaja por pago de impuesto territorial de conformidad a Ley 20.732; debiendo, además, efectuar las devoluciones de los tributos pagados en exceso, debidamente reajustados.

6. No podemos dejar se consignar y mencionar en este resumen uno de los argumentos dado por la Corte de Apelaciones de Santiago recaído en la Sentencia rol 77.252-

3. Al efecto, la sentencia cita a Barría Paredes (2017: 259) y Guastini (1993: 342). 
2018, el que fue eliminado por la CS, y que nos indicaba que no era justo perjudicar a la contribuyente a causa de la supuesta pérdida de uno de los requisitos para gozar de la rebaja, por medio de un acto administrativo atribuible exclusivamente al SII, ya que tanto el avaluó de la propiedad, así como el monto superior establecido por Ley 20.732, como límite para gozar del beneficio, son establecidos por la misma autoridad tributaria.

\section{Esquema comparativo}

Como podemos advertir a partir del análisis del breve cuadro comparativo (tabla 1), surgen ciertas similitudes desde el punto de vista sustantivo entre ambas acciones, permitiendo en definitiva al interesado o recurrente obtener la anhelada tutela de sus derechos fundamentales.

Además, tanto las doctrinas como las jurisprudencias argentina y chilena consultadas para este trabajo, nos permiten anotar como otro elemento común denominador presente en ambas acciones reseñadas el carácter subsidiario de estos remedios procesales, debiendo - según el criterio imperante en una época, ya en retirada- haberse agotado previamente otros medios jurídicos más idóneos o haberse ejercido las vías de orden procesal administrativo existentes, antes que ejercerlas directamente para invocar la protección de determinadas garantías constitucionales.

\section{Conclusiones}

Como primera cuestión, absolutamente destacable, es el hecho de que ambos fallos, reconociendo y aplicando el derecho de tutela judicial efectiva, reconocen y amparan, a su vez, otras potestades fundamentales de las recurrentes, asignándoles a ambas pensionadas la satisfacción y protección de la dignidad como seres humanos y del respeto de su propiedad, especialmente en una etapa de la vida donde la capacidad productiva ha decrecido, así como los ingresos económicos; y por el contrario, los gastos, esencialmente en salud, han aumentado significativamente.

De este modo, la acción o poder jurisdiccional se manifiesta en su máxima plenitud, cuando actúa y resuelve un asunto sometido a su decisión, poniendo coto a una lesión de una garantía constitucional, y así el control jurisdiccional se yergue, colocándose sobre la propia discrecionalidad política o de la administración, como nos decía Rafael Bielsa.

Estimamos además que el ejercicio y conocimiento de ambas acciones cautelares tiene como beneficio el garantizar la validez y la eficacia de los derechos fundamentales reconocidos en ambas Constituciones, generando las condiciones para sostener la tan necesaria seguridad jurídica que debe emanar del sistema.

Ahora, si ambas sentencias las analizamos con el prisma del actual momento político y social en que nos encontramos en Chile, develan uno de los aspectos esenciales de la lábil existencia de nuestro adultos mayores, su precariedad patrimonial para enfren- 
Tabla 1. Esquema comparativo entre ambos casos

\begin{tabular}{|c|c|c|}
\hline Ítem & Argentina & Chile \\
\hline Acción & $\begin{array}{l}\text { Acción meramente declarativa de inconstituciona- } \\
\text { lidad }\end{array}$ & Acción de protección de garantías fundamentales \\
\hline Regulación & $\begin{array}{l}\text { Código Procesal Civil y Comercial de la Nación Argen- } \\
\text { tina, 1981, artículo } 322\end{array}$ & Constitución Política de la República de Chile, 1980, artículo 20 \\
\hline $\begin{array}{l}\text { Presupuestos } \\
\text { procesales }\end{array}$ & $\begin{array}{l}\text { De la citada norma se desprenden los siguientes: } \\
\text { - La vigencia de un estado de incertidumbre sobre } \\
\text { la existencia, alcance y modalidad de una relación } \\
\text { jurídica concreta y la simultánea lesión al régimen } \\
\text { constitucional federal que afecta dicha relación } \\
\text { jurídica discutida o incierta. } \\
\text { - El actor que promueve la acción debe tener interés } \\
\text { jurídico personal, real, concreto, suficiente cierto e } \\
\text { inmediato en la que la falta de certeza contagiada } \\
\text { por la inconstitucionalidad pueda producirle un } \\
\text { daño, perjuicio o lesión actual o inminente. } \\
\text { - Que el demandante no disponga de otro medio } \\
\text { legal para darle fin inmediato a la incertidumbre } \\
\text { constitucional. }\end{array}$ & $\begin{array}{l}\text { Inciso Primero del artículo 20: } \\
\text { - Que exista un acto u omisión ilegal o arbitraria que prive, } \\
\text { perturbe o amenace el legítimo ejercicio de los derechos y } \\
\text { garantías que allí se establecen. } \\
\text { Inciso segundo del artículo 20: } \\
\text { - Que exista un acto u omisión ilegal que afecte el derecho a } \\
\text { vivir en un medio ambiente libre de contaminación. }\end{array}$ \\
\hline $\begin{array}{l}\text { Legitimación } \\
\text { activa }\end{array}$ & $\begin{array}{l}\text { Cualquier persona que afirme y pruebe tener un } \\
\text { interés particular, directo y concreto que tenga la } \\
\text { pretensión de proteger su derecho para evitar una } \\
\text { lesión en forma directa e inmediata. }\end{array}$ & $\begin{array}{l}\text { Cualquier persona que sufra la privación, perturbación o } \\
\text { amenaza al legítimo ejercicio de su derecho 0, en su caso, la } \\
\text { persona afectada en su derecho a vivir en medio ambiente libre } \\
\text { de contaminación o cualquiera a nombre de éstas. } \\
\text { También es posible, que esta acción cautelar sea interpuesta a } \\
\text { nombre de otro, haciendo énfasis en dicha circunstancia. } \\
\text { Respecto de la acción prevista en la Constitución Política de la } \\
\text { República de Chile, 1980, artículo 20, inciso segundo, se prevé } \\
\text { una regla especial en materia de legitimación "pasiva" (el acto } \\
\text { u omisión ilegal debe ser imputable a una autoridad o persona } \\
\text { determinada). }\end{array}$ \\
\hline $\begin{array}{l}\text { Reglas de } \\
\text { Procedi- } \\
\text { miento }\end{array}$ & $\begin{array}{l}\text { Código Procesal Civil y Comercial de la Nación } \\
\text { Argentina, 1981, Libro Segundo, Título I, Capítulo I } \\
\text { (Respectivamente, Libro y Título se denominan «Pro- } \\
\text { cesos de Conocimiento» y «Disposiciones Generales») } \\
\text { y Constitución de la Nación Argentina, 1994, artículo } \\
\text { 116, por la expresa función que tiene reconocida la } \\
\text { constitución al Poder Judicial. }\end{array}$ & $\begin{array}{l}\text { El procedimiento está contenido en el Auto Acordado Sobre } \\
\text { Tramitación y Fallo del Recurso de Protección de las Garantías } \\
\text { Constitucionales contenida en el Acta 94-2015 y sus modifica- } \\
\text { ciones, siendo la última del año } 2018 . \\
\text { Conforme con sus fundamentos, la Corte Suprema hace uso } \\
\text { de sus facultades directivas y económicas, contenidas en la } \\
\text { Constitución Política de la República de Chile, 1980, artículos } \\
76 \text { y siguientes, y Código Orgánico de Tribunales, 1943, artículo } \\
96 \text { número } 4 \text {. }\end{array}$ \\
\hline $\begin{array}{l}\text { Tribunal } \\
\text { Competente }\end{array}$ & $\begin{array}{l}\text { Corte Suprema de Justicia de la Nación Argentina, de } \\
\text { modo originario o derivado. }\end{array}$ & $\begin{array}{l}\text { Corte de Apelaciones respectiva, en primera instancia, y Corte } \\
\text { Suprema, en segunda instancia. }\end{array}$ \\
\hline Efectos & Interpartes. & Interpartes. \\
\hline
\end{tabular}


tar esta compleja etapa de la vida; son quienes, además, deben recurrir a los tribunales de justicia para buscar notoriedad, amparo y defenderse de los atropellos, que en estos casos provienen de agencias del Estado. Entonces cabe preguntarse, ¿cuántos pensionados en nuestras comunidades están en condiciones materiales y anímicas para iniciar acciones judiciales en búsqueda del reconocimiento y amparo que no les prodigamos como conciudadanos? ¿Son justos y protectores los sistemas impositivos y de seguridad social de nuestros países con las personas de la tercera o cuarta edad?

Un segundo aspecto relevante de ambas sentencias es que evitan generar — para el Estado o para la Nación como dicen en la Argentina- nuevos eventos litigiosos derivados de la carga internacional del respeto y promoción de los derechos humanos y de la responsabilidad patrimonial del Estado por actos de la Administración en estos casos, de naturaleza tributaria; por cuanto ambas recurrentes, en el caso de haber sido afectadas con fallos adversos, podrían haber querido perseverar en sus pretensiones jurídicas, recurriendo primero a la Corte Interamericana de Derechos Humanos, denunciando y exponiendo estos casos, bajo la expectativa cierta de que en dicha instancia jurisdiccional internacional sus planteamientos sociales y humanitarios sí serían debidamente amparados; y en segundo lugar, en el orden jurisdiccional interno les asistía el derecho a ejercer las acciones civiles patrimoniales tendientes a establecer e indemnizar los efectos derivados de actos de la Administración por sus actuaciones conculcadoras e ilegales, pero dicho esfuerzo sería aún mucho más incierto.

Es importante acentuar que ambas sentencias reprochan y dejan sin efecto actos de la Administración del Estado; en el caso concreto, de la AFIP y del SII, quienes tienen la difícil (e ingrata) labor de fiscalización y recaudación tributaria en sus naciones. Pero esta cuestión no es menor, ya que quienes han atentado contra la dignidad como ser humano y la propiedad de las justiciables, no es un particular ni cualquier agente, sino que es un ente público, un órgano de la Administración del Estado, así, con mayúsculas, que son los primeros sujetos jurídicos de la sociedad llamados por la Constitución a venerar y promover el total reconocimiento, la mayor aplicación y el máximo respeto de todos los derechos fundamentales de que gozan los ciudadanos en ambas repúblicas.

Una tercera conclusión destacable es la existencia de una notable y constante contradicción de esos órganos públicos que, en el legítimo afán de cumplir con su importante misión recaudatoria para la sociedad, atraviesan regularmente la esfera de indemnidad de los distintos derechos de los cuales son titulares los contribuyentes (en su doble calidad de afectados por el impuesto y como ciudadanos de la República), justificando erradamente y de cualquier modo esos atropellos en sede jurisdiccional como hemos visto, en vez de asumir rápidamente el yerro, reparar el mal causado y volver a actuar según los cauces constitucionales y legales que limitan su complejo quehacer.

En este sentido, algunas de las tantas preguntas de fondo para ambas sociedades podrían ser: ¿Cuánto impuestos queremos recaudar y de qué forma se hará? La presión tributaria y la necesidad de recaudación en ambos Estados ¿puede facultar a las agencias impositivas a desplegar cualquier actuación de fiscalización o de intrusión en contra de los contribuyentes-ciudadanos? Las respuestas a estas y otras interrogantes 
exceden el sentido de este trabajo, pero, al menos como una primera aproximación y esbozo de respuesta, podemos decir que ambos fallos, pronunciados por los tribunales superiores argentino y chileno, son eficaces límites al ejercicio de fiscalización y recaudación tributaria, por cuanto han asentado los correctos principios y reglas de reconocimiento, aplicación y respeto de todos los derechos fundamentales que gozan los ciudadanos en ambas repúblicas.

Desde el plano de las controversias denominadas como «conflicto constitucional o antinomia de principios constitucionales», o colisión de derechos impropia, en estos casos en comento las cortes correctamente optaron - entre una norma fundamental y protectora del Estado, su patrimonio y su potestad impositiva y el pleno reconocimiento, respeto y valoración de la dignidad humana y del derecho de propiedad que se desprende de ella - por proteger y amparar los derechos fundamentales de las personas por sobre los intereses del Estado, a través de la debida argumentación y del desarrollo de un proceso de ponderación.

Como quinta conclusión debemos señalar que en ambos casos, conocidos y resueltos tanto en Argentina como en Chile, no estamos en presencia del fenómeno del «activismo judicial», que tanto incomoda a algunos sectores de la doctrina y del conservadurismo legal. No lo estamos, por cuanto ambas sentencias son respetuosas del principio de separación de poderes; conformándose a los mandatos del Legislador, son cautelosas en el desarrollo de sus ideas y sin perjuicio de ello razonan y argumentan vigorosamente, como lo hemos resumido. Asimismo, no propugnan ni promueven soluciones en exceso imaginativas y no desvarían sobre nuevas instituciones jurídicas o soluciones alejadas del plexo normativo vigente.

Por el contrario, a la luz de los hechos son capaces de un modo magistral - como lo hace la CSJN, y de una forma más estoica, en su estilo, la CS- de ponderar adecuadamente la importancia de los principios y normas vigentes de rango constitucional que permiten dar una justa solución a ambas recurrentes; privilegiando en los casos en concreto, como ya dijimos, los derechos fundamentales de las personas por sobre los intereses del Estado, a través de la argumentación y del proceso de ponderación, postura que si es propia y natural de un órgano que se sienta parte del concepto moderno de Estado constitucional y democrático de Derecho, que creemos existe en ambas naciones.

No obstante lo anterior, no podemos dejar pasar la oportunidad para constatar la significativa diferencia que se devela al momento de revisar el desarrollo de los distintos argumentos y razonamientos constitucionales y legales, vertidos en ambas sentencias: por su parte, la CSJN demuestra un estilo hermenéutico y explicativo amplio, diverso, pletórico de citas doctrinales y jurisprudenciales de los cuales se sirve; y esto no es menor, por cuanto de ese desarrollo y proceso intelectual surge la conformidad para los litigantes, especialmente para la parte perdidosa, de que su caso fue suficientemente estudiado, ponderado, evaluado y resuelto, asignando en el caso concreto una solución justa y racional; desarrollo y proceso exegético que no se aprecia con la misma calidad e intensidad en el fallo de la Corte Suprema chilena. 


\section{Referencias}

Barría PARedes, Manuel (2017). «El elemento de interpretación gramatical. Su origen en Savigny, algunos autores modernos y la doctrina nacional». Ars Boni et Aequi, 7 (2): 257-282.

Guastini, Riccardo (1993). Le fonti del diritto, e l i nterpretazione. Milano: Giuffrè.

\section{Sobre el autor}

Marco Antonio Pontigo Donoso es abogado, licenciado en Ciencias Jurídicas y Sociales de la Universidad Bernardo O’Higgins. Es magíster en Gestión Tributaria (2011) y magíster en Derecho Público (2016), ambos de la Universidad Finis Terrae, y actualmente es alumno del Programa Internacional Intensivo conducente al Grado de Doctor de la Universidad de Buenos Aires, Argentina (2017-2022). Ejerce como profesor de Derecho Administrativo y Derecho Económico en la Universidad de Aconcagua. Su correo electrónico es marcopontigo@gmail.com. (D) https://orcid.org/0000-0001-9940-5216. 
